INTERNATIONAL DESIGN CONFERENCE - DESIGN 2018

https://doi.org/10.21278/idc.2018.0223

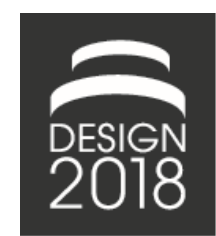

\title{
DATA DRIVEN DESIGN SELECTION AND GENERATION - AN INDUSTRIAL CASE STUDY ON ELECTRIC MOTORS
}

\author{
J. Tüchsen, A. C. Pop, M. Koch, B. Schleich and S. Wartzack
}

\begin{abstract}
This paper presents a novel design selection and generation mechanism for fast and efficient solutionfinding based on the knowledge-based systems concept. Such a mechanism can be fully exploited in the early design phases (i.e. quotation phase), when the supplier has to propose both a technically feasible and pricewise attractive solution to the OEM's request. The benefits of the presented method are a massive time reduction from several weeks to less than one day as well as an improvement of the overall solutions quality as all possible technologies are evaluated parallel.
\end{abstract}

Keywords: selection and generation, electric motor design, data driven design, knowledge based engineering $(K B E)$, decision making

\section{Introduction}

Currently, the automotive industry is characterised by steadily decreasing development times and an increasing variety of models and products. As a result, the development cycles of purchased parts produced by suppliers are shortened too. One example for those supplier parts are electric motors, which are to be optimised for the given mission profile and the operation conditions. Excluding the traction drives, all modern cars are equipped with a huge amount of smaller electric motors performing comfort functionalities or supporting the cars behaviour (Gyselinck and Pop, 2016). Besides comfort, high efforts are done to improve the drive-train's efficiency. Therefore, a variety of previously mechanically actuated functions are being electrified, such as the oil pump, power steering and braking system. In this context, these different electric drives are designed to meet the specific needs of each particular Original Equipment Manufacturer (OEM). Consequently, the supplier has to be flexible enough so as to develop this huge variety of products fast and cost-efficiently to retain its market position.

From the viewpoint of a supplier, the first step of product development is the initial quotation phase when at OEM's request the supplier to propose a technical solution and a corresponding price for a particular drive (see Figure 1), and this without knowing all the details of the project. In accordance with the rule of ten, this quotation phase is essential for the supplier because the decisions taken during this early stage in terms of product feasibility, functionality, costs and other features might have strong repercussions during the later stages of product development. Related to the decreasing development time the quotation phase has to be significantly shortened too.

T. J. E. Miller pointed out, that in 'many cases, new machine designs are evolved from existing ones, by modifying existing laminations and components to minimize the cost of changes in tooling and components' (Miller, 2002). According to this quote, most of the electric motors are rather an adaption of existing ones than complete newly developed designs. In this regard, the novelty of a product can be 
classified into three different degrees. While a novel or original design employs new or combined solution methods to create a complete new product or an innovation, the variant design mainly differs in the geometrical dependencies between the parts. Finally, the adaptive designs are based on the existing solution principle and the products are only adapted to new requirements (Hubka and Eder, 1996; Pahl et al., 2006).

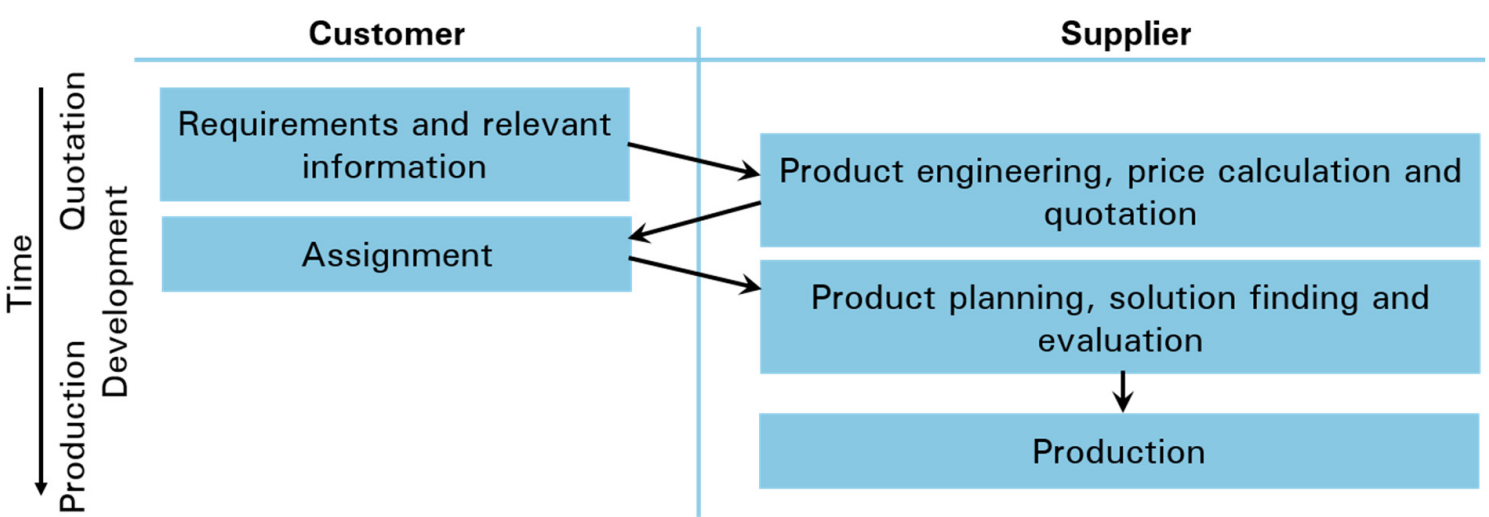

Figure 1. Product development phases including the quotation phase according to Haug et al. (2011) and Pahl et al. (2006)

According to the Mechanical Engineering Industry Association (VDMA), only ten to 30 percent of product developments are generating such original designs. In about 67 percent, a product is adjusted or variated (Naefe, 2012). In this context it is widely acknowledged, that the development of adaptive and variant designs requires far less resources than the development of original designs, since many design steps can be expedited and automated using Knowledge-based Systems (KBS) in combination with parametrisation, scripting, and optimisation. Therefore, there is a strong need for suppliers to early assess, if a new inquiry of the OEM requires an original design or if an existing design can be adjusted leading to an adaptive or variant design. Hence, the aim of this paper is to support early design by developing an automated design method and tool, which allows to drastically reduce the total quotation time and to improve the development efficiency. This method comprises the following steps:

- Check if there are existing solutions for the problem (selector)

- Vary or adjust products based on existing product data (generator)

- Evaluate both existing and newly generated solutions based on the given input data (evaluation)

Therefore, this paper points out appropriate methods of selection, of knowledge-based deciding, and of automated design creation to achieve a time reduction of the quotation phase. The paper is structured as follows. A brief insight into the development and automated design of electric motors is given in Chapter 2 followed by an overview of the background and the related work. Based thereon, the proposed method as well as the industrial case study using electric motors are presented in Chapter 3. Finally, a conclusion and an outlook are given.

\section{Background and related work}

Before answering the given research question, the background and the related work is presented. In this context, firstly a brief introduction to the development and design of electric motors is provided in Section 2.1. After this, an introduction to KBS and knowledge management is given in Section 2.2. The KBS contains the decision-making process including the definition of requirements and goals (Section 2.3). Finally, Section 2.4 gives an overview of the state of the art containing a presentation and discussion of the related work. 


\subsection{Development and design generation of electric motors}

Electric drives (ED) are complex mechatronic systems requiring competences from various fields such as electrical and electronic engineering, information technology as well as mechanical engineering. Further competences are required depending on the type of load that the ED is driving. The ED comprises the motor, the electronic converter and their control. The electric motor as part of the ED usually consisting of laminated rotor and stator core as well as magnets and copper winding is responsible for converting the electric energy into a mechanic force or torque (Miller, 2002).

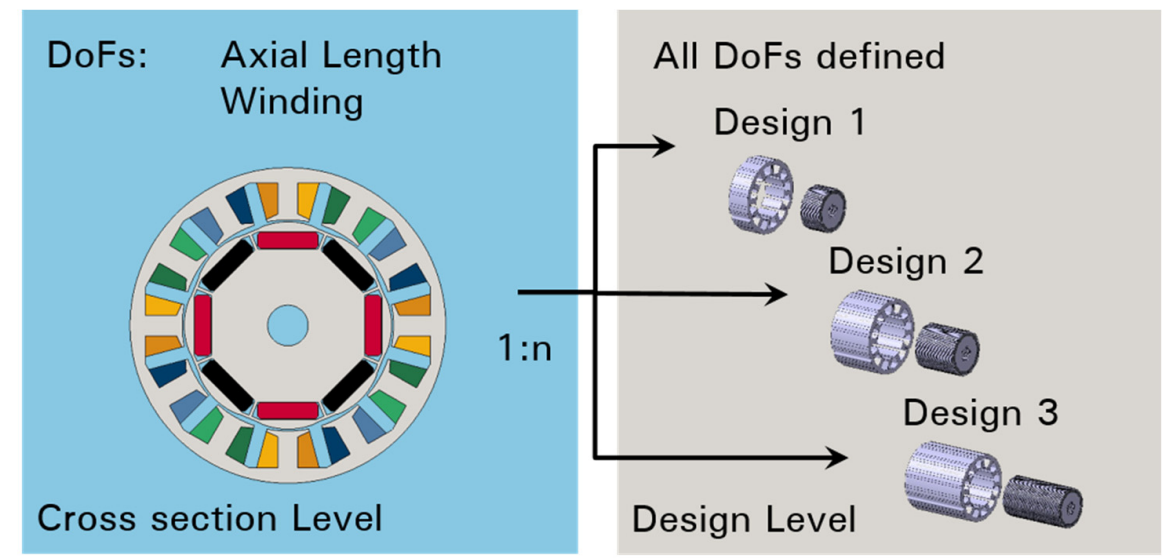

Figure 2. Relationship between cross-sections and designs

For electrical machines with an acceptable ratio between the rotor diameter and axial length, their electromagnetic behaviour is modelled by means of a two-dimensional (2D) finite element analysis (FEA). The 2D FE-Model represents the so-called cross-section (CS). Since electric motors consist of mechanic parts like the rotor, stator and the winding, their geometry can be completely parametrised as shown in (Pop et al., 2017). Using the parametric modelling approach in combination with specialised optimisation methods, the cross-sections can be optimised so as to meet the requirements. The crosssection parameters contain information about the chosen topology, the geometry, magnetic fields etc. Following the 2D-electromagnetic FE analysis the 3D parameters such as motor length, lamination thickness or the winding configuration have to be provided. If all these characteristics are defined, the design results from a certain cross-section after efficiently varying the available degrees of freedom (DoFs). In general, to each cross-section a variety of designs can be assigned, but each design is subordinated to one cross-section (1:n relationship, see Figure 2).

'Ideally, one does not need to develop a completely new automated production line for each project, therefore a design which can be used with minor adjustments for more projects, in a similar power range, is preferred.' (Pop et al., 2017). Therefore, the design DoFs such as the axial length and the winding are modified to meet the working points from the different requirements by keeping the same cross-section (Pop et al., 2017). Because of the relationship between cross-section and design, there is the possibility to select a sufficient cross-section first and afterwards to generate a suitable design. Using the mathematical dependencies, tailored-to-the-problem optimisers and model order reduction methodologies, the design generation process takes less than one minute.

\subsection{Knowledge-based systems and knowledge management}

To digitalise and automate tasks like problem-solving or decision-making, which are originally performed manually, it is common to use expert systems or KBS (Studer et al., 1998). KBS are computer programs including a knowledge base that are able to make intelligent deductions on limited task areas (Puppe, 1991). In those systems, the user usually has access via the user interface (often a graphical and interactive module) to the inference mechanism. Together with the context and the knowledge base, this mechanism provides results at user's request. The chosen approach by the mechanism is explained to the user in the explanation facility (Styczynski et al., 2017). 


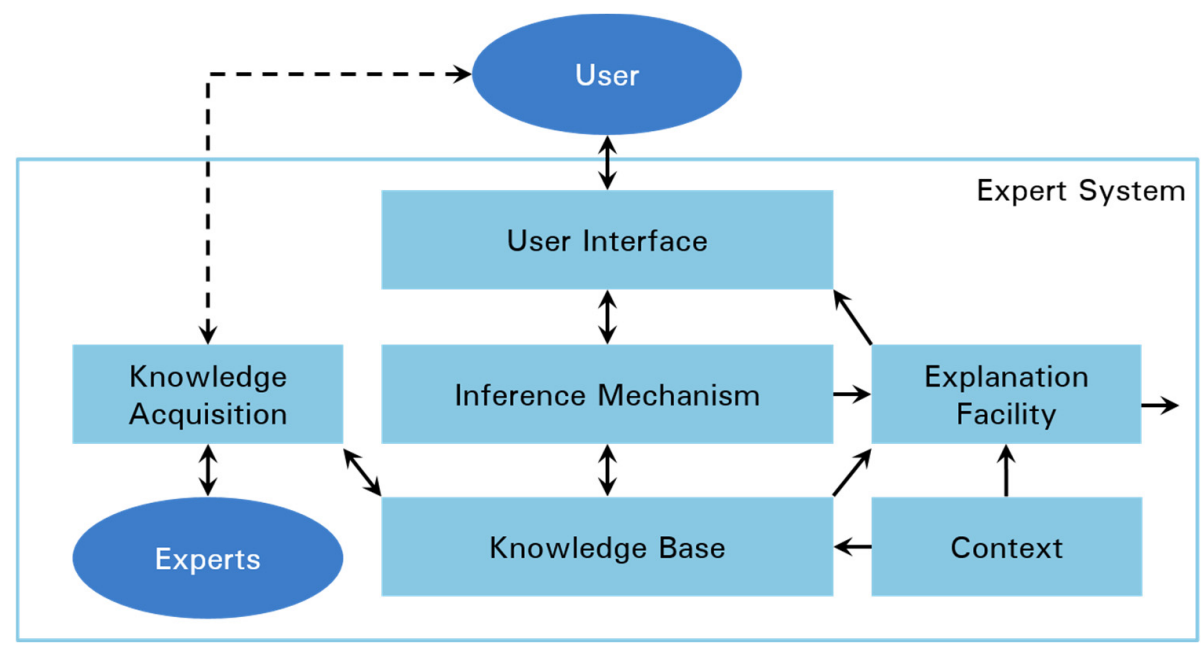

Figure 3. Architecture of the KBS according to Styczynski et al. (2017)

The architecture of the KBS is shown in Figure 3. As the whole KBS works only with a knowledge base, this knowledge must be acquired, interpreted and represented by the experts first (VDI 5910-2, 2017). As all the knowledge in a company is distributed on its employees, the documents and calculation programs, knowledge management methods are used to identify and collect the knowledge first. This process can be supported by the common methods of monitoring the working methods in project teams or divisions, performing interviews, surveys and workshops or using statistics and sociograms (VDI 5610-1, 2009). In addition, knowledge could also be gained automatically from case data or scientific literature (Puppe, 1991), which is becoming more significant with the advent of machine learning using data mining methods (Beierle and Kern-Isberner, 2006). As all the collected knowledge is purposed to be used in the KBS, it must be formalised in a computer readable language such as facts, rules, object descriptions, heuristic data and conditions (Styczynski et al., 2017). Then, the formalised knowledge could be used to automate tasks and to assist the user e.g. in the set-up of geometry and FE simulation models (Kestel et al., 2016), in plausibility checks (Sprügel et al., 2015), in the Body-In-White area of automotive design (Chapman and Pinfold, 1999) or in decision-making as it is described in the next section.

\subsection{Decision-making process}

Despite the fact, that there are rules, guides and standards in the products design, often the developers tend to decide intuitively or subconsciously using their experiences from further evaluation process. Nevertheless, those decision and the preconditions should be well considered (VDI 2223, 2004). One method for rational requirements based reasoning and selection is the decision-making process, its steps explaining the necessary phases and the corresponding input information. The decision-making process as formalised by Baker et al. (2001) can be split up into eight steps starting with the definition of the problem (1), the determination of the requirements (2) and the establishing of the goals (3) that the solution to the problem should meet. The defined problem can have a variety of solutions, i.e. a request can be fulfilled by different products, the so-called alternatives. Next step is dedicated to the identifications of these alternatives (4), followed by the goals driven development of the evaluation criteria (5). After an extensive treatment of steps 1-5, this logic can be implemented in a decision-making tool (6). Using an KBS for this tool as it is described in Section 2.2., an automatic knowledge-based selection process can be implemented (7). Finally, the proposed solution(s) should be verified (8). Presenting a concept for a new decision-making app called iDecide, Luft et al. (2016) demonstrate the actual relevance of decision-making automation by giving an example that shows a concept decision for motors used in a new rotary hammer.

Particularly important for this process is the definition of the requirements, the goals and the evaluation criteria (i.e. steps 2, 3 and 5). Not only that the meaning of requirements and goals diverges, they need a different treatment too. On the one hand, requirements contain statements about the product, such as 
weight or size, and on the other hand, they contain statements like deadlines and cost targets (Pahl et al., 2006). Goals are defined as 'broad statements of intent and desirable programmatic values' (Baker et al., 2001). While requirements are the must-haves of the product (Baker et al., 2001), which could be understood as demands, goals are more like wishes, which should be taken into account (Pahl et al., 2006) and describes the wants and desires (Baker et al., 2001). To conclude, the requirements are working like filter functionalities sorting out all the non-fitting solutions, whereas the goals rank the products belonging to the given wants and desires. In the most cases, products should meet more than one goal and in return, usually there is no alternative, which meets all the given goals. This results in a multi-criteria decision problem and there is the necessity to compare the alternatives with each other (Baker et al., 2001). One common method for the evaluation and the comparison of alternatives is the technical and economic evaluation (VDI 2225, 1990). Kurtoglu and Campbell (2007) developed an automated evaluation mechanism of automatically generated design alternatives, which is analysing the designer's decision-making in the development process of a new product and is able to compare a huge number of designs using a detailed model of system components and design parameters.

\subsection{Related work}

Starting with the product configurators, which enable assembling customised products and continuing with selection tools and mechanisms capable to pick out the most suitable product for a given application, all these have a common purpose: selecting the best product for a special application. In this section, a brief overview of the existing solutions is presented and differentiating features in regard with the solution proposed in this paper are highlighted.

Currently, product configurators with a web-based interface are used to provide the customer a selfconfigured, individualised product e.g. cars, furniture or shoes as given in (Stormer, 2007). Furthermore, configurators with a higher level of complexity exist for internal use by experts within the development units in order to automate work of humans in sales and design processes. Using configurators can lead to time reductions from several days to less than one day (Haug et al., 2011). Although these configurators are KBS providing possible solutions, they are able to supply only pre-programmed solutions based on a limited number of pre-calculated combinations. In this matter, the selection and generation mechanism proposed in this paper acts conversely as it has to evaluate, to which extent the given solutions are suitable for a given application.

While having a similar research question, Feldhusen et al. (2010) use a data mining method to compare the specifications of a new order with existing orders. Modifying the component with the highest similarity in the specification, their aim is to gain the fewest cost changes. For mechanic products, this aim inherently leads to similar products with a simple amount of changes. Particularly, for mechatronic products such as the electric motors, the fluctuating prices and availabilities of the different magnet materials (e.g. rare earths) and the possibility to realise the same motor characteristics using different technologies, might not always lead to the most suitable and cheapest solution.

The Institute of Industrial Electronics and Electrical Engineering of the Riga Technical University modelled a selection mechanism to choose the optimal motors to be used in electric industrial systems (Kunicina et al., 2008; Ribickis et al., 2008; Chaiko et al., 2008). The presented selection mechanism included in the 'Gudrais inženieris' software is especially created for choosing a motor for water pump stations. It leads to time savings for the staff engineer, as it is able to sort out inappropriate designs and suggest good ones. The used database is filled with motor catalogue data, as the intention is choosing an existing motor from a defined solution pool (Chaiko et al., 2008). Furthermore, the elaborated rules inside the KBS for choosing a motor having as main filter the efficiency are described in (Ribickis et al., 2008). At least, Kunicina et al. (2008) have the purpose to suggest an optimal selection of electrical equipment depending on given technical process data. The Riga Technical University presents with their work an appreciate solution mechanism based on a database containing existing motors. A similar approach is examined by Egbuna and Basson (2009), who researched a selection mechanism for electric actuators. As the aim of this paper is selecting possible solutions first and then generating new motor designs based on the given requirements and goals in combination with the selection results, it requires the formulation of a new software tool. While the software 'Gudrais inženieris' employs a defined catalogue of existing motors with their efficiencies, characteristic curves and parameters, the new tool 
presented in this paper is able to vary both geometry and electric properties of each motor so to propose the optimal motor fitting at best the OEMs objectives. Summarising the related work it becomes apparent, the very high significance of the topic addressed in this work for the electric motor industry. While, there are already existing solutions containing configurators and selection mechanism, they cannot be one-to-one transferable to the problem dealt with hereafter.

\section{Method for the data driven design selection and generation - an electric motor case study}

The novel principle of the design selector and generator (DSG) proposed in this work is shown in Figure 4. Following the customer's request for a product, all necessary input data is collected (Section 3.1). Hence a set of constraints is created and they are further used to select/filter only the suitable crosssections and designs from the whole set available in the database (selector). Further, the design generator creates new cost and efficiency optimised designs based on the selected cross-sections by modifying the DoFs (axial length and winding). As the generator is developed for fast provision of motor designs with parts for standardised manufacturing, this step is done for each suitable cross-section. Afterwards, the new generated designs are implemented into the design database in order to be filtered and loaded in the next customer requests. Both functionalities selector and generator are interdependent and they are described in Section 3.2. In the next step the suitable loaded and generated designs are evaluated in order to rank the motors regarding the customers and suppliers interests. The output being the design(s) fitting at best the specification and goals, which can be presented to the customer (Section 3.3).

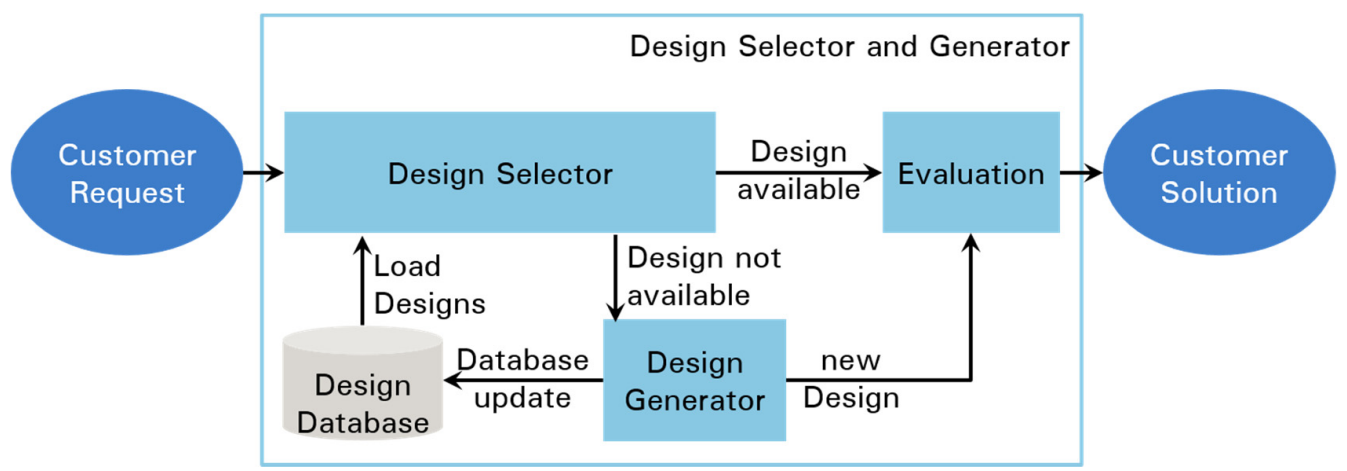

Figure 4. Principle of the design selector and generator

In this case study, the DSG is used (exemplary) to design a motor for an auxiliary oil pump, having a required power of $165 \mathrm{~W}$ and a limited diameter outer diameter $D_{\max }$ (resulted from the limited assembly space) at given battery voltage, maximum allowed current and temperature. Finally, for a comprehensive price calculation a production cycle of four years is assumed with one million pieces per year.

\subsection{Requirements and goals of the design selector and generator}

The goals and requirements in the DSG are based on the inputs comprising the customer specifications, production data and controlling values, as well as the existing knowledge and core competences (see Figure 5). The latter along with the used manufacturing technology can be decisive factors choosing the type of motor that has to be developed. The customer specifications include requirements such as working points, power and efficiency, weight and costs. However, the customer has to provide information about the steady-state torque-speed curve, the inertia of the load and the pattern of operation, as they are needed to develop a robust motor (Hughes, 2006). Costs are calculated from the chosen material volume and its price per volume, defined using daily-actualised cost tables derived from the market. Production data containing the manufacturing technology and the capacity of the lines have a high impact on the final costs and thus on the overall technical solution. The number of turns allowed in the slots of the stator vary based on the used winding process technology. For example, for the cheaper needle winding process a high amount of space has to be kept clear as the needle has to surround the stator tooth. A higher amount of turns is possible by using the costlier single tooth winding process 
where the stator is assembled after the winding process (Pop et al., 2017). Due to the inherently lower efficiency of the motors employing low-cost technologies, they have to be designed either with a larger outer diameter or with a combination of more length and higher input power, in order to fulfil the same working points. Therefore, decisions on costs require both information on the used manufacturing technologies as well as the used materials, as e.g. the design selection can be influenced by a less balanced manufacturing line due to the lower investments needed to acquire new equipment.

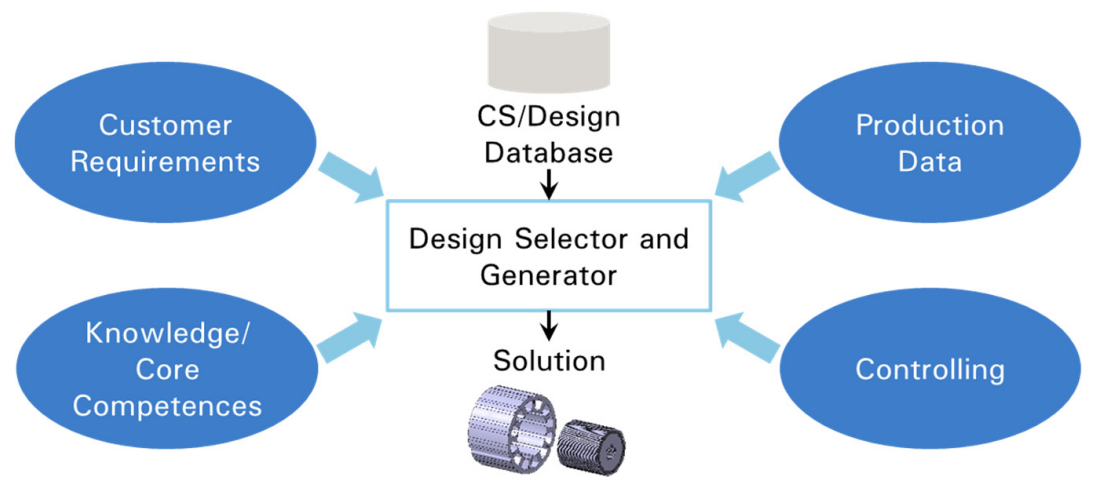

Figure 5. Inputs and outputs of the design selector and generator

The high variety of existing motor technologies makes it difficult to choose the right configuration without defining key performance indicators (KPI). One such indicator can be the continuous power rating as shown in Figure 6 (Hughes, 2006). Generally, this variety can be streamed down to a reduced number of topologies by considering the core competences available in the company. Particularly the chosen topology is a brushless 3 ph permanent magnet synchronous machine (PMSM) as it is the "standard" motor choice in the automotive industry thanks to its higher efficiency, compactness and robustness. In this topology, the rotor consists out of magnets and laminated core whereas the also laminated stator core carries the windings (Miller, 2002). One possible cross-section of this topology can be found in Figure 2, Section 2.1.

\begin{tabular}{|c|c|c|c|c|c|c|c|}
\hline \multirow{2}{*}{$\begin{array}{l}\text { Motor } \\
\text { type }\end{array}$} & \multicolumn{6}{|c|}{ Continuous rating } & \multirow[b]{2}{*}{$10 \mathrm{MW}$} \\
\hline & $10 \mathrm{~W}$ & $100 \mathrm{~W}$ & $1 \mathrm{~kW}$ & $10 \mathrm{~kW}$ & $100 \mathrm{~kW}$ & $1 \mathrm{MW}$ & \\
\hline 3-ph Induction & $\vdots$ & & & & & & $\vdots$ \\
\hline 1-ph induction & & & & & & $\vdots$ & \\
\hline 3-ph Exc. Synch. & $\vdots$ & $\vdots$ & & & & t & \\
\hline 3-ph P. M. Synch. & $\vdots$ & & $i^{\prime}$ & & & $\vdots$ & \\
\hline 3-ph Reluctance & $\vdots:$ & & & & & $\vdots$ & \\
\hline Conventional d.c. & $\vdots$ & 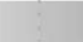 & . & & & & $\vdots$ \\
\hline Brushless d.c. & & $\therefore$ & i & & & $\vdots$ & \\
\hline Ironless Rotor d.c. & & & $\vdots$ & & & $\vdots$ & \\
\hline Switched reluctance & $\vdots$ & $:$ & $\div$ & & $\vdots$ & $\vdots$ & \\
\hline Stepping & & & & & & $\vdots$ & \\
\hline
\end{tabular}

Figure 6. Continuous power rating for various types of motor (Hughes, 2006)

The output of the DSG should be an overview of the designs fitting best as well as recommendations in terms of either using an existing design and cross-section, or a new generated design based on an existing cross-section. In case there is no available design, the system triggers the need for a new development, which means a new cross-section, obtained at the end of an optimisation loop (Pop et al., 2017). The new cross-section will be the base for the new design. 


\subsection{Selection and generation process}

As the solution must meet all the formulated requirements, a filter mechanism could be proposed to sort out the not acceptable products (see Figure 7a). Those demands have to be expressed by quantitative values such as length in millimetres or descriptive indications (VDI 2225, 1990). By using constraints such as the product's diameter $D<D_{\text {max.allowed }}$ or Boolean operations, the feasible solutions can be easily found (Pahl et al., 2006).

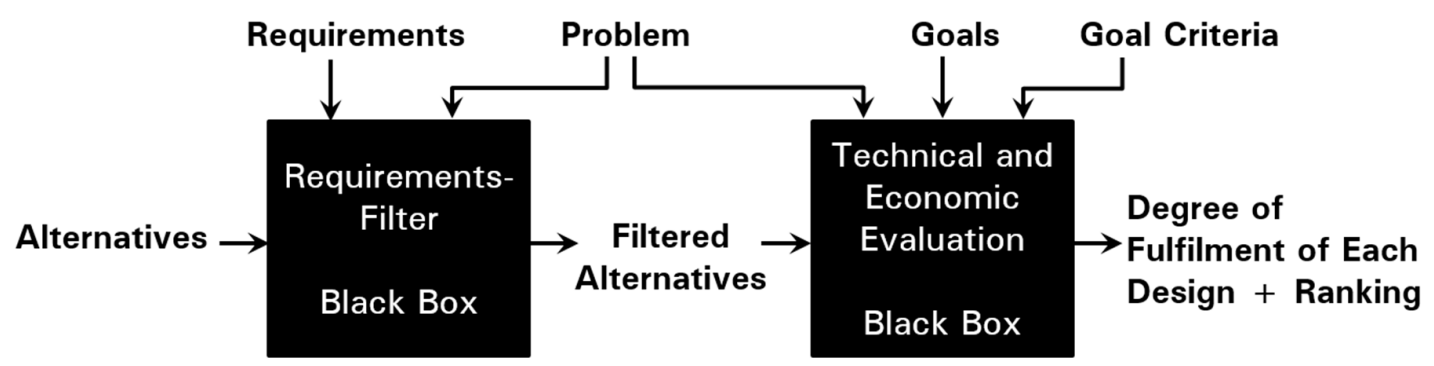

(a)

(b)

Figure 7. Black boxes for the requirements-filter (a) and for the technical and economic evaluation (b)

However, performing a constraint optimisation by strictly applying the customer requirements may yield the wrong results as a rejected design which is slightly under an imposed threshold (e.g. in terms of torque ripple) might perform better when considering other indicators (e.g. average torque, costs, etc...). Therefore, the possibility to allow (within some limits) for a violation of the constraints should be considered, knowing that the customer is always open when it comes to innovative solutions. Such designs can be defined as pending within the generated pareto-front. The final design selection can be done based on a weighted objective function by combining the customer requirements while assuming the project constraints. The filtered alternatives are then evaluated according to their goal achievement. For this purpose, the technical and economic evaluation method (VDI 2225, 1990; Pahl et al., 2006) respectively the concept-scoring matrix and the Pugh concept selection (Ulrich and Eppinger, 2012) is used in combination with the goal criteria. As all the defined requirements must be met by the alternatives, they are not part of the technical and economic evaluation. The result of this method is the degree of fulfilment for each alternative and additional the ranking between those solutions as shown in Figure $7 \mathrm{~b}$. There are criteria like efficiency or weight, which sometimes are defined with a special minimum value and sometimes they are just defined by 'as low/high as possible'. Depending on the definition, those criteria can be kept either as a requirement or as a goal. Regularly, goals are defined as minimum requirements, which are allowed to being exceeded to the positive side and wishes, which should be considered. (VDI 2225, 1990). Therefore, in the technical evaluation step, the technical value $\mathrm{x}$ is calculated based on the following Equation 1, which describes the relation between the sum of the characteristics scores $p_{n}$ and the maximum score of the ideal solution $p_{\max }$.

$$
x=\frac{p_{1}+p_{2}+p_{3}+\cdots+p_{n}}{n \cdot p_{\max }}=\frac{\bar{p}}{p_{\max }}
$$

The scores are usually differentiated into five stages e.g. $0=$ insufficient, $1=$ still sufficient, $2=$ sufficient, 3 = good 4 = very good (ideal) (VDI 2225, 1990; Ulrich and Eppinger, 2012). The second part of the solution rating is the economic evaluation, which is mainly based on the manufacturing effort presented by costs of materials (VDI 2225, 1990; Ulrich and Eppinger, 2012). Additionally, manufacturing data like existing capacity per product line or used manufacturing technology especially using disruptive technologies as rapid prototyping influence the costs. The selection of the appropriate manufacturing technology and the calculation of the overall costs are based on the number of pieces requested from the customer and should be recognised in the economic evaluation (Scheer et al., 1990). The developed selector consists of a total of three requirements filter and one overall technical and economic evaluation. Between the first two filters and the third filter, the automated design generation 
is implemented. This mechanism shown in Figure 8 is now presented systematically using the case study example.

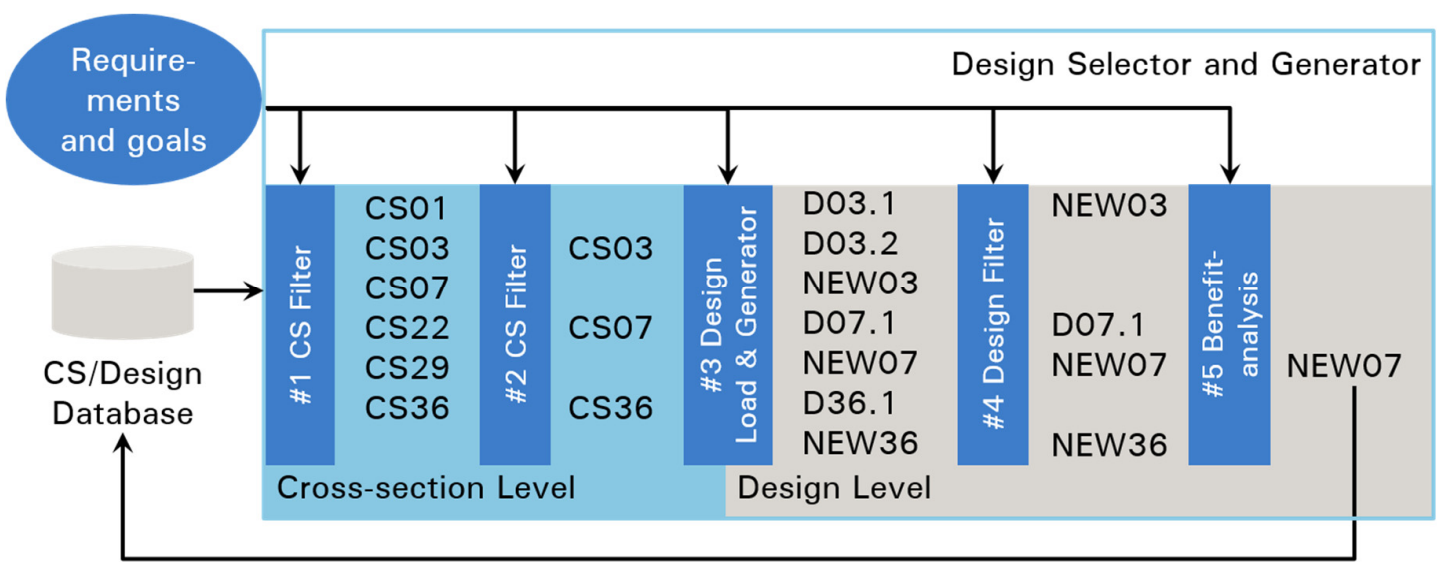

Figure 8. Overall design selection and generation mechanism

\subsubsection{Cross-section level}

In the first step of Figure 8, all existing cross-sections in the database are filtered by the customer requirements (\#1). It is recommended to use the power range as the first and the size as the second filter parameter (Hughes, 2006). In this paper, the required power of $165 \mathrm{~W}$, yields as suitable motor topology the brushless type, which also fits to the defined core competences. Another requirement from the customer concerns the assembly space as a maximum diameter $D_{\max }$ is allowed, all other cross-sections having a diameter exceeding $D_{\max }$ being rejected. These customer requirements are met by a total of six existing cross-sections as shown in Figure 8. Additionally, one has to consider that too small motors cause thermal problems due to the rather large power loss density. To prevent the selection of those motors, a knowledge-based filter is subsequent, which wipe out all cross-sections with a diameter below $0,75 \cdot D_{\max }(\# 2)$. After the second filter, three cross-sections remain. CS03 and CS07 have the same diameter $\left(0,96 \cdot D_{\max }\right)$ but differ in the number of poles, i.e. ten for CS03 and eight for CS07 and in the magnet quality, which is the cheaper ferrite for CS03 and the expensive rare earth for CS07. Both cross-sections use the needle winding technology. Finally, CS36 has a smaller diameter $\left(0,82 \cdot D_{\max }\right)$, and its rotor contains ten rare earth magnets whilst its stator is also winded by means of needle winding technology.

\subsubsection{Design level including evaluation}

Streaming from the cross-section down to the design level (see Figure 8), the automated design generation process is used to calculate the necessary number of turns and the axial length such that the motor fulfils the specified working points. As a result, for each cross-section a new cost optimised design is created (namely NEW03, NEW07 and NEW36). Moreover, there are often designs based on the filtered cross-section that are in series production or already in sample state and validated by tests. Regularly, it can be said that cost-targeted optimisations result in motors with a shorter length and thus lower material costs, but they tend to have lower efficiencies. However, comparing both the new and the existing designs (from previous projects) it could occur that they are quite similar.

Therefore, existing designs should be also loaded and evaluated in order to save costs and manufacturing effort (\#3). In this study, CS03 has two existing designs; CS07 and CS36 have one existing design each, which along with the new designs, gives a total of seven designs. The existing designs are further filtered with regard to the fulfilment of the working points, battery voltage, maximum allowed current, etc. (Filter \#4). This results in only one suitable existing design D07.1 and the new ones NEW03, NEW07 and NEW36. The final selection being done based on a technical and economical evaluation (\#5). The following criteria: costs, efficiency, torque reserve (i.e. the difference between torque in WP and the required value), relative torque ripple (i.e. the ratio between peak-to-peak torque ripple and the average 
torque) and weight are used for the best design assessment. By applying the previously described five score stages, the evaluation of each design is performed and reported in Table 1a.

Table 1. Scores in the technical evaluation (a) and the weighting of those criteria (b)

(a)

\begin{tabular}{|c|c|c|c|c|c|}
\hline $\begin{array}{r}\text { Crit. } \\
\text { Score }\end{array}$ & $\begin{array}{c}\text { A Overall } \\
\text { Costs }\end{array}$ & B Efficiency & $\begin{array}{c}\text { C Torque } \\
\text { Reserve }\end{array}$ & $\begin{array}{c}\text { D rel. Torque } \\
\text { Ripple }\end{array}$ & E Weight \\
\hline 4 & $/^{*}$ & $>76 \%$ & $>5 \%$ & $<2 \%$ & $<400 \mathrm{~g}$ \\
\hline 3 & $/^{*}$ & $>72 \%$ & $>4 \%$ & $<4 \%$ & $<450 \mathrm{~g}$ \\
\hline 2 & $/^{*}$ & $>68 \%$ & $>3 \%$ & $<6 \%$ & $<500 \mathrm{~g}$ \\
\hline 1 & $/^{*}$ & $>64 \%$ & $>2 \%$ & $<8 \%$ & $<550 \mathrm{~g}$ \\
\hline 0 & $/^{*}$ & $<64 \%$ & $<2 \%$ & $>8 \%$ & $>550 \mathrm{~g}$ \\
\hline
\end{tabular}

(b)

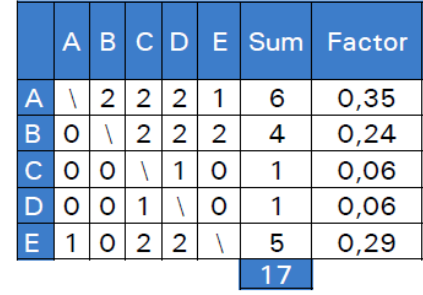

The costs represent the sum of material costs, development costs, production line change effort to enable the manufacturing of the new designs and finally the production costs themselves. As there is a distinction in relevance between those characteristics, there is the possibility to add a weighting factor each term of the given equation using pairwise comparison (Table 1b). The assessment procedure performed on all the remaining designs (Table 2) shows that NEW07 is the best solution in the considered exemplary scenario. Finally, those results are displayed in the results matrix (Figure 9). Now the experts have the possibility to investigate the various solutions and they can either follow the tool's recommendation by choosing the best design, or develop a new design. The latter can be done by adapting the settings of different filters.

Table 2. Technical evaluation for the optimised and existing filtered designs

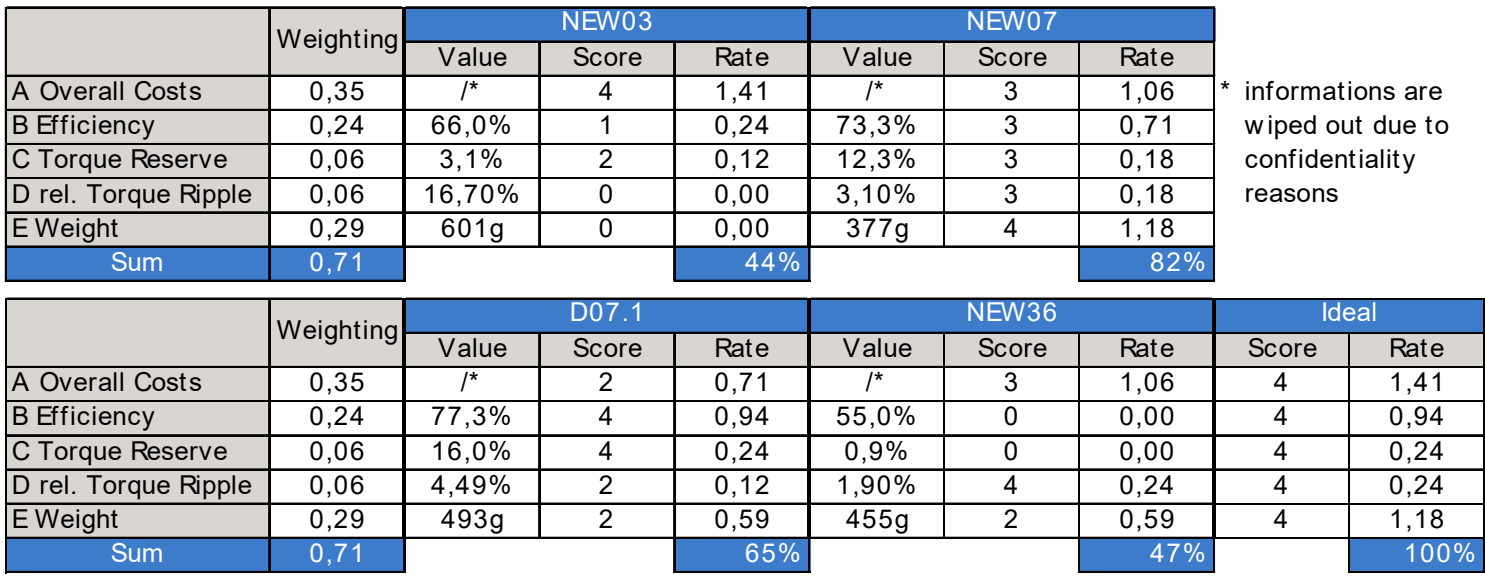

\subsection{Discussion}

The industrial case study shown here, presented the successful development of a new design selector and generator mechanism which allows for reducing the quotation time and for improving the design's quality. Based on input data such as customer requirements, knowledge, production and controlling data, this novel mechanism chooses the most sufficient cross-section from over 35 existing ones. Furthermore, cost optimized designs are generated and are evaluated automatically regarding the input data and comparing existing motor designs. At least, the used KBS is able to recommend the best alternative or new development. In the study, the design NEW07 was generated and evaluated with an overall goal suitability of $82 \%$ while meeting all given requirements. Taking into account more than the given five criteria or using nine instead of five differentiation steps as described in (Ulrich and Eppinger, 2012) may have an influence on the overall suitability percentage. Therefore, the manually set scores have to be considered well. In order to a full automation of this process, which is compatible with each customer request, data analytical methods could be used to set the scores in consideration of e.g. sensitivity analysis automatically. 


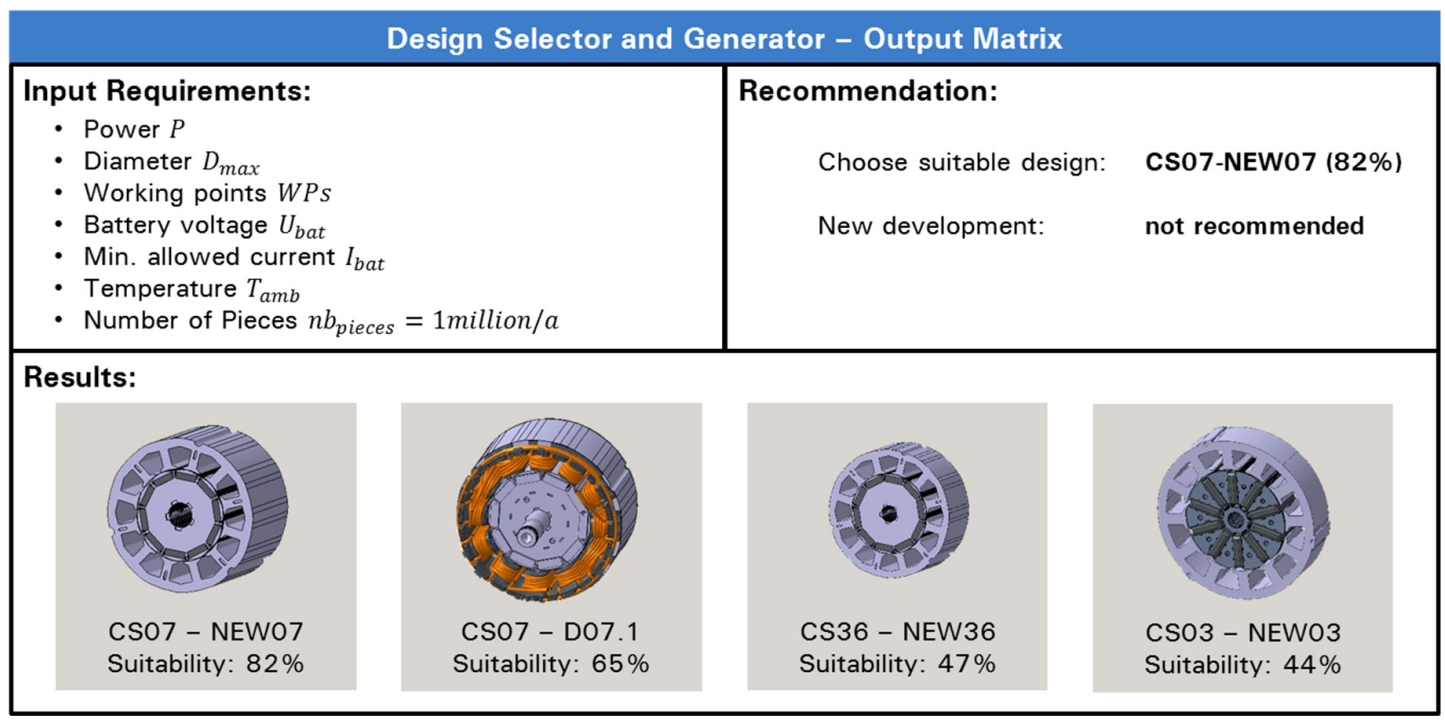

Figure 9. Design selector and generator results matrix

\section{Conclusion and future work}

This paper proposed a novel mechanism for automated and data driven design selection and generation. As both selection and generation happen in less than one day, the quotation phase can be reduced tremendously. Additional, this tool has a high impact on the finally chosen solution and design's quality. In the beginning of automotive projects, there often is a high uncertainty about the requirements, which forces the OEM to define thresholds based on their experiences. In the most cases, the only fixed requirement is the cost of the motor and some requirements such as the design space are changeable through discussions. In the future, this tool is to be expanded in order to reduce the uncertainty in the beginning of a new development by giving data driven design proposals to both customer and supplier.

\section{References}

Baker, D., Bridges, D., Hunter, R., Johnson, G., Krupa, J. et al. (2001), Guidebook to Decision-Making Methods (WSRC-IM-2002-00002), U.S. Department of Energy.

Beierle, C. and Kern-Isberner, G. (2006), Methoden wissensbasierter Systeme: Grundlagen - Algorithmen Anwendungen, Vieweg, Wiesbaden. https://doi.org/10.1007/978-3-8348-9116-7

Chaiko, Y., Zhiravaecka, A., Kunicina, N., Galkina, A. and Ribickis, L. (2008), "Modelling Decision Making Procedure for Pump Electric Drives Chosen for Water Pump Stations", Electronics and Electrical Engineering, Vol. 82 No. 2, pp. 59-64.

Chapman, C.B. and Pinfold, M. (1999), "Design engineering - a need to rethink the solution using knowledge based engineering", Knowledge-Based Systems, Vol. 12 No. 5-6, pp. 257-267. https://doi.org/10.1016/s09507051(99)00013-1

Egbuna, C. and Basson, A. (2009), "Electric actuator selection design aid for Low Cost Automation", Proceedings of ICED 2009 / the 17th International Conference on Engineering Design, Vol. 6, Stanford, California, USA, August 24-27, 2009, The Design Society, Glasgow, pp. 43-54.

Feldhusen, J., Nagarajah, A. and Schubert, S. (2010), “A Data Mining Method For Selecting The Suitable Existing Product Variant As A Development Base For A New Order", Proceedings of the DESIGN 2010 / 11th International Design Conference, Dubrovnik, Croatia, May 17-20, 2010, The Design Society, Glasgow, pp. 895-904.

Gyselinck, J.J.C. and Pop, A.C. (2016), "Finite-Element and Lumped Parameter Modelling and Simulation of Permanent Magnet Synchronous Machines - From Academic State of the Art to Design Office Practice", [online] Tutorials from the 22nd International Conference on Electrical Machines / ICEM'2016, Lausanne, Switzerland, September 4-7, 2016. Available at: http://w1.icem.cc/2016/index.php/tutorials (accessed 22.11.2017).

Haug, A., Hvam, L. and Mortensen, N.H. (2011), "The Impact Of Product Configurators On Lead Times In Engineering-oriented Companies", Artificial Intelligence for Engineering Design, Analysis and Manufacturing, Vol. 25 No. 2, pp. 197-206. https://doi.org/10.1017/s0890060410000636 
Hubka, V. and Eder, W.E. (1996), Design Science: Introduction to the Needs, Scope and Organization of Engineering Design Knowledge, Springer, London. https://doi.org/10.1007/978-1-4471-3091-8

Hughes, A. (2006), Electric Motors and Drives: Fundamentals, Types, and Applications, Elsevier Ltd., Amsterdam.

Kestel, P., Schneyer, T. and Wartzack, S. (2016), "Feature-Based Approach For The Automated Setup Of Accurate, Design-Accompanying Finite Element Analyses", Proceedings of the DESIGN 2016 / 14th International Design Conference, Dubrovnik, Croatia, May 16-19, 2016, The Design Society, Glasgow, pp. 697-706.

Kunicina, N., Galkina, A., Ghaiko, Y. and Ribickis, L. (2008), "Development of an Intelligent Algorithm for Electrical Motor Choice for Industrial Systems", Power \& Electrical Engineering, Vol. 22, pp. 78-85.

Kurtoglu, T. and Campbell, M.I. (2007), "Exploring The Worth Of Automatically Generated Design Alternatives Based On Designer Preferences”, Proceedings of ICED 2007 / 16th International Conference on Engineering Design, Paris, France, August 28 - 31, 2008, The Design Society.

Luft, T., Lamé, G., Ponn, J., Cardinal, J.S.-L. and Wartzack, S. (2016), “A Business Model Canvas For Idecide How To Design A New Decision Making App?”, Proceedings of the DESIGN 2016 / 14th International Design Conference, Dubrovnik, Croatia, May 16 - 19, 2016, The Design Society, pp. 1523-1532.

Miller, T.J.E. (2002), SPEED's Electric Motors: An outline of some of the theory in the SPEED software for electric machine design. [online] University of Glasgow. Available at: https://de.scribd.com/doc/33998196/ Miller-T-J-E-SPEED-s-Electric-Motors (accessed 17.11.2017).

Naefe, P. (2012), Einführung in das Methodische Konstruieren für Studium und Praxis, Springer, Wiesbaden. https://doi.org/10.1007/978-3-658-00002-8

Pahl, G., Beitz, W., Feldhusen, J. and Grote, K.-H. (2006), Engineering Design: A Systematic Approach, Springer, Berlin Heidelberg. https://doi.org/10.1007/978-1-84628-319-2

Pop, A.C., Gyselinck, J.J.C., Pinto, D.E. and Vintiloiu, I. (2017), “Optimization of Low-Power Brushless PMMachines for Automotive Applications with Focus on High Volume Mass Production”, IEEE Transactions on Industrial Electronics, Vol. 64 No. 12, pp. 9767-9775. https://doi.org/10.1109/TIE.2017.2698367

Puppe, F. (1991), Einführung in Expertensysteme, Springer, Berlin. https://doi.org/10.1007/978-3-662-00706-8

Ribickis, L., Kunicina, N. and Ghaiko, Y. (2008), "Electric Motor Selection Method Development for Efficiency Increasing of Electrical Drives Systems", Power an Electrical Engineering, Vol. 22, pp. 70-77.

Scheer, A.-W., Bock, M. and Bock, R. (1990), Expertensystem zur konstruktionsbegleitenden Kalkulation, Institut für Wirtschaftsinformatik der Universität Saarbrücken, Heft 73.

Sprügel, T., Hallmann, M. and Wartzack, S. (2015), "A Concept For FE Plausibility Checks In Structural Mechanics", Proceedings of the NAFEMS World Congress 2015 (NWC 2015) incorporating the 2nd International Conference "Simulation Process and Data Management" (SPDM), San Diego, CA, June 21-24, 2015, NAFEMS, Hamilton, UK.

Stormer, H. (2007), "Kundenbasierte Produktkonfiguration”, Informatik Spektrum, Vol. 30 No. 5, pp. 322-326. https://doi.org/10.1007/s00287-007-0177-1

Studer, R., Benjamins, V.R. and Fensel, D. (1998), "Knowledge engineering: Principles and methods", Data \& Knowledge Engineering, Vol. 25 No. 1-2, pp. 161-197. https://doi.org/10.1016/s0169-023x(97)00056-6

Styczynski, Z.A., Rudion, K. and Naumann, A. (2017), Einführung in Expertensysteme: Grundlagen, Anwendungen und Beispiele aus der elektrischen Energieversorgung, Springer, Berlin Heidelberg. https://doi.org/10.1007/978-3-662-53172-3

Ulrich, K.T. and Eppinger, S.D. (2012), Product Design and Development, McGraw-Hill, New York.

VDI 2223 (2004), Systematic embodiment design of technical products, Beuth Verlag, Berlin.

VDI 2225 Part 3 (1990), Technisch-wirtschaftliches Konstruieren: Technisch-wirtschaftliche Bewertung, Beuth Verlag, Berlin.

VDI 5610 Part 1 (2009), Knowledge management for engineering: Fundamentals, concepts, approach. Beuth Verlag, Berlin.

VDI 5610 Part 2 (2017), Knowledge management for engineering: Knowledge-based engineering (KBE), Beuth Verlag, Berlin.

Johann Tüchsen, M.Eng.

Brose Fahrzeugteile GmbH \& Co. KG, Würzburg, Drives Simulation

Ohmstraße 2a, 97076 Würzburg, Germany

Email: johann.tuechsen@brose.com 